Sharif University of Technology
Scientia Iranica
SCIENTIA
I RAN I CA

\title{
The effect of carbon nanotubes/bioglass nanocomposite on mechanical and bioactivity properties of glass ionomer cement
}

\author{
M.R. Foroughi ${ }^{\mathrm{a}, *}$, M. Khoroushi ${ }^{\mathrm{b}}$, R. Nazem ${ }^{\mathrm{c}}$ and E. Akbarian Tefaghi ${ }^{\mathrm{d}}$ \\ a. Dental Materials Research Center, School of Dentistry, Isfahan University of Medical Sciences, Isfahan, Iran. \\ b. Dental Materials Research Canter and Department of Operative and Art, School of Dentistry, Isfahan University of Medical \\ Sciences, Isfahan, Iran. \\ c. Department of Operative and Art, School of Dentistry, Isfahan University of Medical Sciences, Isfahan, Iran. \\ d. School of Dentistry, Islamic Azad University, Khorasgan Branch, Isfahan, Iran.
}

Received 12 November 2015; received in revised form 20 August 2016; accepted 8 October 2016

\author{
KEYWORDS \\ Nanocomposites; \\ Glass ceramics; \\ Glass ionomer cement; \\ Carbon nanotubes; \\ Bioglass 45S5.
}

\begin{abstract}
The aim of this study is to manufacture and characterize Carbon Nanotubes (CNTs)/bioglass (BG) to improve the mechanical and biocompatibility properties of GlassIonomer Cement (GIC). The powder of Glass-Ionomer Cements was prepared through fusion, and carbon nanotubes and bioactive glass were manufactured through fusion and added to the cement to improve its mechanical and bioactive properties. To evaluate the biological adaptation of manufactured composites, they were placed in Simulated Body Fluid (SBF). Finally, the compressive strength test and erosion test showed that the mechanical properties of Glass-Ionomer Cement are two-fold of those when $1 \%$ carbon nanotubes are used $(\mathrm{P}<0.001)$. The electrical conductivity of $\mathrm{BG}$ increased by 8 orders of magnitude after incorporation of $6.35 \mathrm{wt} \%$ of CNTs compared with pure BG. Short-duration tests were used in this study for preliminary evaluation of the effect of incorporating CNTs on fibroblasts. Analysis of cell proliferation, viability, and phenotype expression of PDL (periodontal ligament) fibroblasts showed inhibition on CNT-BG-GIC composite surfaces. Based on the results, the material exhibited optimized properties which can be used in restorative dental materials and lining and sealing fillers in dentistry.

(C) 2016 Sharif University of Technology. All rights reserved.
\end{abstract}

\section{Introduction}

Glass-Ionomer Cement (GIC) is one of the most important bioceramic materials used in reconstructive procedures in dentistry. The most important advantages of GICs are their color match with teeth and high biological adaptation with hard tissues. Glass-Ionomer Cement was manufactured and introduced by Wilson and Kent (1971) in England and became popular due to its favorable properties, including formation of a physiochemical bond with hydrophilic enamel

\footnotetext{
*. Corresponding author.

E-mail address: mr.foroughi@dnt.mui.ac.ir (M.R. Foroughi)
}

and dentin structures, low micro-subsidence, long-term fluoride release, capacity to absorb and store fluoride, low thermal expansion, and bio-adaptation with pulp and periodontal tissues [1,2]. Glass-Ionomer Cements are organic-based materials that result from an acidbased reaction between alumina silicate glass powder and polyacrylic acid [3]. Its semi-clear appearance resembles that of the teeth, and it can be attached to tooth structures. GICs adhere to enamel and dentin permanently, closing the gap between this material and tooth tissue, preventing penetration of cariogenic agents and secondary caries. Compared to other reconstructive materials, GICs exhibit higher biological adaptation to the oral cavity without adverse biological 
reactions. GICs are extensively used to repair tooth structure in clinical dentistry. Some of the advantages of Glass-Ionomer Cement include biological adaptation, low toxicity, fluoride release, and limitation of microleakage around restorations [4].

Some of the disadvantages of GICs include weak mechanical and physical properties such as low polishability, dehydration, additional absorption of humidity during the initial stages of setting, and low fracture and flexural strengths [5].

In recent years, attempts have been made to improve the mechanical and physical properties of Glass-Ionomer Cements. Al-Angari et al. used zinc to improve the flexural strength and toughness of this material [6]. Moshavernia et al. reported that incorporation of nano-hydroxyapatite and nano-fluorine apatite to Glass-Ionomer Cement can increase mechanical properties, including compressive and tensile strengths, and improve the bond to dentin [7].

Carbon nanotubes were introduced by Kroto et al. [8] and Ijima [9] in 1991. They can significantly improve the positive properties of polymeric, metallic, ceramic and composite materials, and their structural strength [10,11]. Multi-Walled Carbon Nanotubes (MWCNTs) exhibit proper biological adaptation and bioactivity. A combination of unique mechanical properties and bioactivity renders CNTs as one of the most favorable secondary phases in manufacturing bioceramic nano-composite materials [12-18]. CNTs have recently been discovered, and no long-term studies have been carried out on their effect on human health; therefore, researchers are cautious to recommend it for medical applications. However, there have been attempts to show their effect on stem cells [19], human gingival fibroblasts [20], and osteosarcoma cell lines [21]. The effect of the method used to manufacture CNTs on their cytotoxicity in vitro and in vivo has been dealt with in various review articles [22-24]. Studies by Mei et al. [25] showed an increase in the proliferation of periodontal ligament cells up to $30 \%$ using their MWCNT incorporated GTR membrane; however, gingival epithelial cells exhibited less attachment. Zhang et al. [26] used surface-modified SWCNTs to reinforce a commercial resin-based dental composite, which yielded encouraging results. In addition, the morphology of carbon nano-materials has a great role in the bioactivity of such materials. CNTs have a needle-like fibrous shape; therefore, their shape might affect the bioactivity of the final product. Studies have shown that CNTs have a detrimental effect on lysosomal membranes in cells [27-30]. In addition, the CNT content of biomaterials can greatly affect their bioactivity. The bioactivity of nano-composites is predominantly a function of the interaction between the cells and the nano-phase as the matrix is bioactive in itself. Although a high CNT content can have various advantages, including better mechanical and electrical properties, their effect on cell environments is yet to be elucidated.

Bioactive glasses have various applications in modifying and repairing damaged tissues, because they have the capacity to be attached to surrounding tissues through a layer of hydroxyapatite carbonate that is formed on a layer of bioactive glass. Bioactive glasses exhibit higher bioadaptation than calcium phosphates. They also have a mixture of calcium and phosphate salts, similar to their ratio in bones and tooth. Therefore, they are considered good choices as dental implants and for repairing bone defects $[31,32]$. Yli-Urpo et al. incorporated $30 \%$ bioglass into GIC, which led to a $45 \%$ increase in compressive strength and bioactivity of the cement [33]. On the other hand, Bioglass 45S5 (BG) with osteoconductive, antibacterial, antiinflammatory, and potential angiogenic effects has been reported to be an excellent choice for manufacturing bone tissue scaffolds [34-38]. Bioglass was introduced in 1971 by Larry Hench and attracted great attention due to its superb biological properties as a regenerative medicine $[39,40]$. Since the surfaces of biomaterials directly contact the biological environments of the human body, the surface properties of BG have an important role in their biomedical applications. Therefore, studies are under way to find techniques to modify their surface characteristics in order to improve their biocompatibility and bioactivity [41].

The manufacture of bioglass composites with nanostructures has attracted a lot of attention in the literature [42], with particular focus on the mechanical, electrical, and thermal properties of carbon nanomaterials. They have found applications in a wide array of biomedical fields [43-57].

Based on the issues discussed above, the main aim of the present study is to manufacture and incorporate carbon nanotubes and bioactive glasses into GIC in order to produce a composite to improve the mechanical and bioactive properties of this material. In addition, in order to investigate biocompatibility of the composite, PDL (periodontal ligament) fibroblasts were used to evaluate their cell morphology cultured on different composite samples.

\section{Materials and methods}

\subsection{Preparation of ceramic constituent of glass-ionomer cement}

The initial materials used in the present study to manufacture the ceramic component of GIC included $23 \mathrm{~g}$ of aluminum oxide $\left(\mathrm{Al}_{2} \mathrm{O}_{3}\right), 41 \mathrm{~g}$ of $\mathrm{SiO}_{2}, 10 \mathrm{~g}$ of $\mathrm{SrF}, 13 \mathrm{~g}$ of $\mathrm{AlPO}_{4}$, and $13 \mathrm{~g}$ of $\mathrm{CaF}_{3}$ with $99.8 \%$ purity. All the ingredients were the products of Merck Company (Germany). The ceramic constituent of GIC was manufactured through the fusion method. First, 
the weight percentages of the oxides mentioned above were prepared and mixed in a mill containing alumina bullets to integrate the size of powder particles. Then, the predetermined amounts of the materials were placed in an electrical fusion furnace [AZAR1500] and heated up to $1400^{\circ} \mathrm{C}$ for three hours at a thermal rate of $5^{\circ} \mathrm{C} / \mathrm{min}$. The fusion of ingredients was carried out through a palatine bush. After fusion of crystalic materials in a planetary ball-mill [Fretch, Pulverisette-5] in zirconia chambers which are resistant to erosion, numerous parameters were attended to during a process, such as the ratio of bullets to powder (1:3), number of bullets, and rotation of speed during (250 rpm) breaking operation [58,59]. The resultant powder at this stage was passed through a sieve with 200 meshes $(76 \mu \mathrm{m})$, after which it was considered a glass powder based on ASTM E11-95 standard. The resultant powder was the ceramic component of GIC. Subsequently, the ceramic powder was mixed with polyacrylic acid, and the GIC samples were prepared for the subsequent tests. To fabricate the samples, GIC powder was scattered on a cold slope. Then, half of the scattered powder was slowly added to the polymeric liquid (polyacrylic acid) and mixed for 20 seconds. Then, the remaining part of GIC powder was completely mixed in 20 seconds. The final mix had a wet and bright surface and its modification took 30-45 seconds. The mixing stages are shown in Figure 1. The final mix was poured in aluminum molds measuring $6 \mathrm{~mm}$ in height and $4 \mathrm{~mm}$ in diameter. The samples were retrieved from the molds after cooling.

\subsection{Synthesis of bioactive glass}

In the present study, a bioglass with predetermined weight composition was manufactured (41.04 $\mathrm{g}$ of $\mathrm{SiO}_{2}, 29.25 \mathrm{~g}$ of $\mathrm{CaO}, 23.26 \mathrm{~g}$ of $\mathrm{Na}_{2} \mathrm{O}$, and 1.78 $\mathrm{g}$ of $\left.\mathrm{P}_{2} \mathrm{O}_{5}\right)$ through the fusion method. First, the primarily, each one of the constituents was considered in 45S5 composition. Based on calculation of molecular weights of the desired oxides, they were mixed with the following weights: $46.13 \mathrm{~g}$ of $\mathrm{SiO}_{2}, 48.03 \mathrm{~g}$ of $\mathrm{CaCO}_{3}, 41.64 \mathrm{~g}$ of $\mathrm{Na}_{2} \mathrm{CO}_{3}$, and $3.59 \mathrm{~g}$ of $\mathrm{H}_{3} \mathrm{PO}_{4}$. Due to involvement of $\mathrm{SiO}_{2}$ particles, the mixtures have mechanical alloy generation for 30 minutes, and

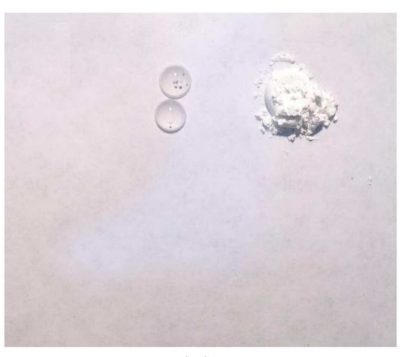

(a)

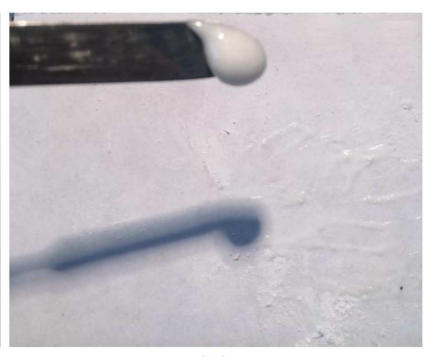

(b)
Figure 1. Preparation stages of GIC ceramic powder: (a) Before; and (b) after. they were pressed to produce more bioglass powder. The cut pieces were poured into an alumina plant and in a furnace. Tried-and-true method led to the definition of a temperature of $1400^{\circ} \mathrm{C}$ for fusion of this composition. The furnace was in an oxidative setting and the maximum velocity increased to $1400^{\circ} \mathrm{C}$. After achieving this temperature, the furnace was preserved in this state, and the plant was retrieved from the furnace and poured on a cupper or steel plate. The fluid was quickly cooled down, and a uniform glass was manufactured. The resultant glass underwent mechanical alloying for 10 hours. Finally, powderlike particles were produced. One of the stages of manufacturing a porous structure consists of preparing stable slurry through proper additions.

\subsection{Manufacturing composite and characterization}

In this study, we used Multi-Wall Carbon Nanotubes (MWCNTs), $-\mathrm{COOH}$ functional group (US Research Nanomaterials, Inc.). CNT particles have an internal diameter of 3-5 $\mathrm{nm}$ and an external diameter of 5$15 \mathrm{~nm}$, with a length of $\sim 50 \mu \mathrm{m}$. To prepare the desired composite (GIC-CNT-BG), a definite value of GIC was carefully weighed. Then, multi-wall carbon nanotubes with 1 and 2 wt\%, as well as bioactive classed of 45S5 with $10 \mathrm{wt} \%$, were incorporated into GIC powder. An amalgamator was used to completely mix GIC, carbon nanotubes, and bioactive glasses for 30 second. In order to harden the composite powder, the polymeric solution of polyacrylic acid with 1.5:1 ratio (powder-toliquid) was added to it at room temperature in special cylindrical molds. It should be noted that due to the presence of carbon nanotubes, the final material was almost black.

The special surface value of GIC was measured through special surface measurement test (Brunauer Emmett Teller (BET), Sorptometer Kelvin 1042, Italy). XRD method was used to analyze the phase structure and glasses of the ceramic constituent of GIC (Bruker, D8 ADVANCE Germany). XRF analysis (Bruker, S4 PIONEER, Germany) was used to confirm the presence of oxides in the final composition of GIC based on the desired weight percentage. FTIR analysis (JASCO, 6300, Japan) was applied to investigate the chemical structure, formation of intermolecular bonds and distribution of mechanism of nanotubes, PAA acid and tartaric acid. Scanning Electron Microscopy (SEM, Philips XL-30, Netherlands) was used for this study; samples were coated with gold under an argon atmosphere. Subsequently, mechanical test was carried out to determine the flexural strength of resin-based ceramic materials using a universal test machine (K21046, Walter + bai, Switzerland), measuring $2 \times$ $2 \times 25 \mathrm{~mm}$ based on ANSI/ADA- No. 12 (ISO 1567) standard with application of force at a crosshead speed 
of $0.5 \mathrm{~mm} / \mathrm{min}$ to measure and define flexural strength of composite samples. Erosion test was carried out on the samples with the dimensions defined for flexure by Pin on Disk wear machine (Sayesh Co., Isfahan, Iran) to determine resistance to erosion in samples. To study the size, morphology and microstructure of the ceramic constituent, GIC composite, and bioactivity of hardened composite were analyzed by placing the composite in SBF environment for two weeks. To this end, the absorption level of $\mathrm{Ca}^{2+}$ in the SBF solution was measured using the Atomic Absorption Spectroscopy (AAS) method (AAS-Perkin Elmer CoA-Analyst-300). The size and morphology of nanocomposite were evaluated, and the apatite crystals absorbed on the surface of composite were observed under a scanning electron microscope (Mira 3-XMU).

\subsection{In vitro biocompatibility studies}

\subsubsection{Cell culture and analysis}

The morphological organization of fibroblasts exhibits cell-substrate adhesion; therefore, it can be used as a sensitive indicator of the biocompatibility of a biomaterial. To evaluate the cell compatibility of GICCNT-BG used from PDL fibroblast cells. The protocol of the study was approved by the Ethics Committee of School of Dentistry, Isfahan University of Medical Sciences. Three cryogenic vials with frozen human PDL fibroblasts from 3 unidentified individuals were thawed and transferred into tissue culture flasks (Nunc, Thermo Scientific, Denmark) containing the culture medium. The culture medium was Dulbecco's Modified Eagle Medium (DMEM) (Gibco, Grand Island, NY) supplemented with $10 \%$ bovine fetal serum (Hyclone, Thermo Scientific, Logan, UT, USA) and 1\% antibiotic/antimycotic solution (10,000 U of penicillin, $10 \mu \mathrm{g}$ of streptomycin, and $25 \mu \mathrm{g}$ of amphotericin B per $\mathrm{mL}$ ). The cells were incubated at $37^{\circ} \mathrm{C}, 5 \% \mathrm{CO}_{2}$, and $100 \%$ relative humidity. After obtaining a confluent monolayer, the cells were trypsinized and subcultured. The PDL fibroblast cells from the 4th-7th passage were used in this study.

\subsubsection{Preparation of material extracts}

After mixing, as previously described under aseptic conditions, a total of $0.2 \mathrm{~g}$ of fresh cements was transferred into a well of 24-well tissue culture plate. The specimens from three test groups and GIC group were incubated at $37^{\circ} \mathrm{C}$ and $100 \%$ relative humidity for 30 minutes, whereas GIC specimens were incubated for 4 hours under the same condition. After incubating, the specimens were exposed to ultraviolet light for 30 minutes for sterilization. One $\mathrm{mL}$ of complete DMEM was transferred into each well containing each specimen and incubated for 72 hours. After incubation, the extract from each well was transferred into a centrifugal vial for centrifugation for 5 minutes. The supernatant was collected and serially diluted 1:1 with DMEM to achieve a total of 4 concentrations. A series of extracts were prepared at different concentrations to observe a possible dose-response relationship.

\subsubsection{Cell viability test (MTT assay)}

Human PDL fibroblasts were transferred into 96-well plates at 20,000 cells/well and incubated for 24 hours to pave the way for attachment. Subsequently, $100 \mu \mathrm{L}$ of the extract was transferred into the tissue culture well. Cells with $100 \mu \mathrm{L}$ culture medium served as a control. After incubation, cell viability was evaluated by 3-(4,5dimethylthiazol-2-yl)-2,5-diphenyltetrazolium bromide (MTT) assay. Briefly, the extract from each well was discarded, washed once with $100 \mu \mathrm{L}$ of PhosphateBuffered Saline (PBS), supplemented with $50 \mu \mathrm{L}$ of MTT solution (1 $\mathrm{mg} / \mathrm{mL}$ in PBS), and incubated for 2 hours. Then, the MTT solution from each well was discarded and $100 \mu \mathrm{L}$ of isopropanol was added to each well. The plates were then shaken for 30 minutes to dissolve the crystals. Reduced MTT was then measured spectrophotometrically at $570 \mathrm{~nm}$ in a microtiter plate reader (BIO-TEK Instrument Inc, Winooski, VT). The Optical Density (OD) of the test and control wells were calculated by using the following equation:

$$
\% \text { Cell viability }=\frac{\mathrm{OD} \text { value of test well }}{\mathrm{OD} \text { value of control well }} \times 100 \text {. }
$$

The results were expressed as means \pm Standard Deviations (SD). Data were analyzed with one-way ANOVA at a significance level of $P<0.05$. Post-hoc Scheffé's tests were carried out. The experiments were repeated six times for each cell line.

\section{Results and discussion}

\subsection{Structural analysis of nanocomposite}

3.1.1. Measurement of special surface

The special surface of the manufactured GIC particles was measured through BET method at $0.73 \mathrm{~m}^{2} / \mathrm{g}$. By supposition of sphericity and uniform size of all the particles, the average size of GIC particles is calculable from Eq. (2):

$$
D=6 / s \times \rho,
$$

where $D$ is the mean size of particle in micron, $s$ is the measured number by BET machine, and $\rho$ is the density of powder particle. On the other hand, the special surface value of synthesized MWCNT was calculable at $233 \mathrm{~m}^{2} / \mathrm{g}$.

\subsubsection{Phase structure evaluation (XRD)}

Figure 2 shows the XRD pattern of GIC powder sample and GIC powder with $1 \%$ carbon nanotubes and $10 \%$ 


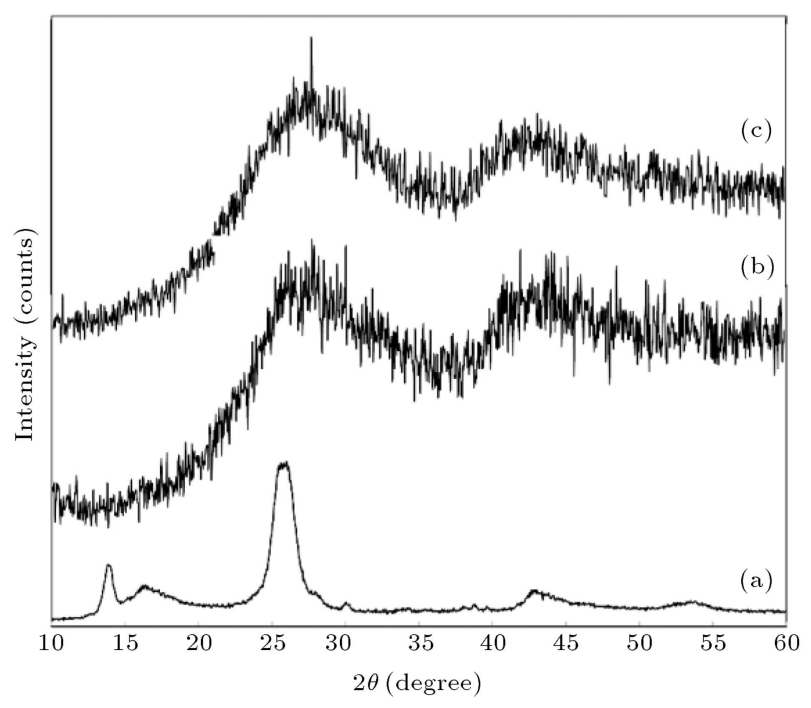

Figure 2. XRF pattern of sample: (a) Multi-walled carbon nanotubes; (b) GIC powder; and (c) GIC powder with $1 \%$ carbon nanotubes and $10 \%$ bioactive glasses.

bioactive glasses. As shown, in XRD pattern of a GIC powder sample, no peak is observed, indicating amorphous structure of GIC powder, while in XRD pattern, the composite sample with carbon nanotubes and bioactive glasses exhibited a spectrum of $2 \theta=$ $25-30$, and the observed peak was associated with carbon structure. The mean size of particles can be calculated from modified Scherre equation [60]:

$$
\beta=k \lambda / L .1 / \cos \theta,
$$

where $L$ is the size of crystal beads, $\lambda$ is the $x$-ray wavelength, and $\beta$ is the maximum peak width in half of its height (radian). The degree of crystallinity of the powder is determined through Eq. (4):

$$
X_{c}=1-\left(V_{112 / 300}-I_{300}\right),
$$

where $X_{c}$ is crystallinity of the powder, $V_{112 / 300}$ is the depth of valleys of diffraction, and $I_{300}$ is the intensity of peak.

\subsubsection{Initial analysis through XRF method}

Initial analysis was carried out using the XRF method on GIC powder to confirm the presence of oxides in the composition based on weight percentages. The results with appropriate estimations, shown in Table 1, were similar to calculated weight percentages of the sample. The results of XRF test showed that chemical composition of the ceramic component of GIC manufactured through fusion method was similar to the expected weight percentages with sufficient estimation.

Table 1. Weight percentages of GIC powder compositions.

\begin{tabular}{cccccc}
\hline Components & $\mathrm{SiO}_{2}$ & $\mathbf{A l}_{2} \mathbf{O}_{3}$ & $\mathbf{A l P O}_{4}$ & $\mathbf{C a F}_{2}$ & $\mathbf{S r F}$ \\
\hline Contents (\%) & 39 & 25.5 & 16.5 & 12 & 7 \\
\hline
\end{tabular}

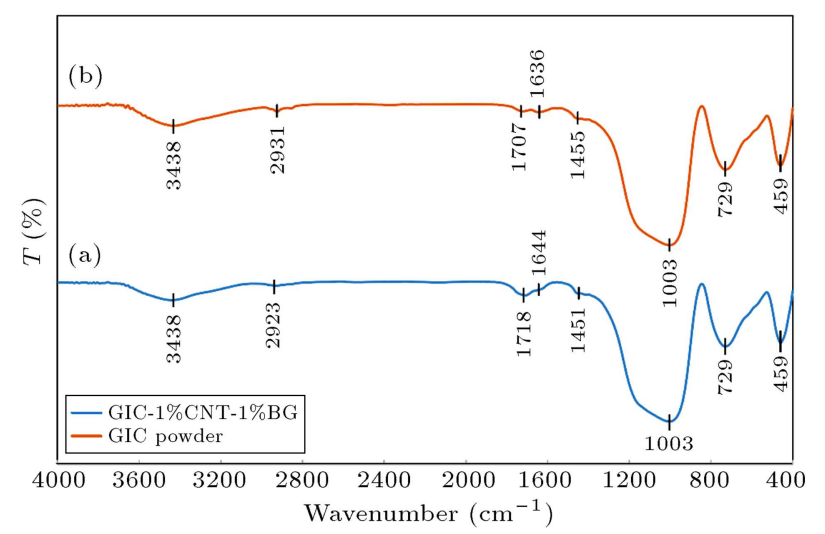

Figure 3. FTIR Spectrum: (a) GIC powder; and (b) GIC composite powder with $1 \%$ carbon nanotubes and $10 \%$ bioactive glass.

\subsubsection{Evaluation of chemical structure through FTIR} The results of FTIR analysis of GIC power sample and GIC powder with $1 \%$ carbon nanotubes and $10 \%$ bioactive glass are shown in Figure 3 . Since the analyzed compositions were powders and had not been mixed with PAA, peaks of hydroxyl at $3594 \mathrm{~cm}^{-1}$ were weakly observed. On the other hand, $1718 \mathrm{~cm}^{-1}$ spectrum in Figure 3(a) is related to - $\mathrm{COOH}$ functional group of MWCNT, which is relatively weak in the GIC powder spectrum.

The infrared spectrometry of GIC sample and its composite after being mixed with polymeric liquid (polyacrylic acid) are shown in Figure 4. The presented peaks at $3594 \mathrm{~cm}^{-1}$ represent stretching motions of hydroxyl ions in the crystal network of GIC network and its composite. In addition, the observed peaks at $2935 \mathrm{~cm}^{-1}$ represent stretching motions of $\mathrm{C}-\mathrm{H}$ in alkane group, the diversity in location, and intensity of interaction which shows some interactions between MWCNT and matrix. On the other hand, a bent peak at $1476 \mathrm{~cm}^{-1}$ represent C-H (alkanes). $1243 \mathrm{~cm}^{-1}$ and

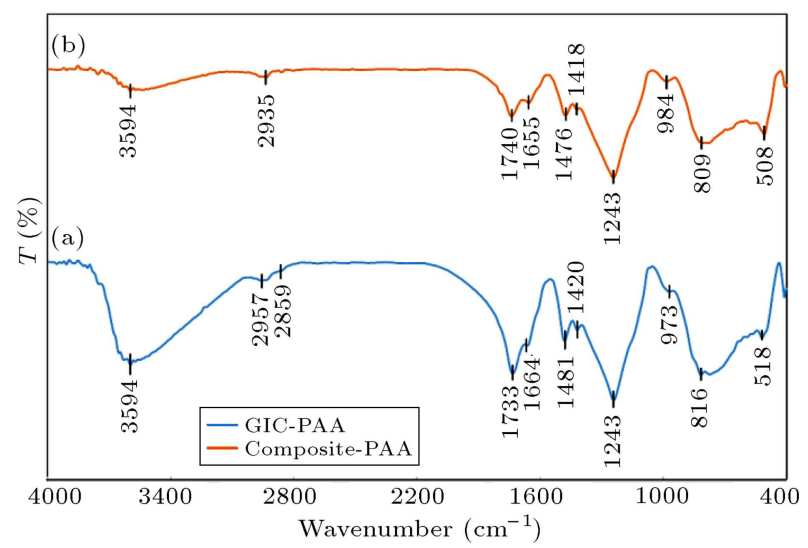

Figure 4. FTIR Spectrum: (a) GIC samples; and (b) GIC composite powder with $1 \%$ carbon nanotubes and $10 \%$ bioactive glass after combination with polymeric liquid of polyacrylic acid. 
$1733 \mathrm{~cm}^{-1}$ peaks (in Figure 4(a)) are associated with stretching band of $\mathrm{C}=\mathrm{O}$ and $\mathrm{C}-\mathrm{O}$ groups of polyacrylic acid, respectively. In the spectrum of Figure 4(b), the observed peak of the regions of absorptive peaks at $1243 \mathrm{~cm}^{-1}$ displays the interaction of acid with MWCNT. By considering the chemical structure of PAA and tartaric acid, $\mathrm{C}=\mathrm{O}$ bond at $1655 \mathrm{~cm}^{-1}$ represents Van der Waals weak bond between the acid and MWCNT.

\subsubsection{SEM evaluation}

The images taken by electron microscope of the ceramic constituents of GIC and EDX analyses are presented in Figure 5 at different magnifications. What can easily be observed from these images is the irregular size of glass particles which are under $100 \mathrm{~nm}$. Such a size range has also been reported by other researchers [7]. The size of glass particles plays an important role in their performance after being mixed with polymeric liquid (polyacrylic acid). In Figure 6, nanocomposite composition with carbon nanotubes, bioglass nanopar- ticles, and its EDX analysis is shown. As shown in Figure 6, carbon nanotubes are scattered in the whole composition, which might significantly affect the mechanical properties of manufactured cements.

\subsubsection{Flexural strength test}

Table 2 presents the results of the analysis of flexural strength of GIC with different weight percentages of carbon nanotubes. These results showed that incorporation of carbon nanotubes with $1 \mathrm{wt} \%$ has no effect on decreasing the flexural strength of GIC. A decrease in flexural strength at values higher than $1 \mathrm{wt} \%$ of CNT

Table 2. Mean compressive strength of GIC for different weight percentages of CNT particles $(n=3)$.

\begin{tabular}{cccc}
\hline $\begin{array}{c}\text { GIC } \\
\text { (wt\%) }\end{array}$ & $\begin{array}{c}\text { Bioglass } \\
(\mathbf{w t} \%)\end{array}$ & $\begin{array}{c}\text { CNT } \\
\text { (wt\%) }\end{array}$ & $\begin{array}{c}\text { Compressive } \\
\text { strength (MPa) }\end{array}$ \\
\hline 100 & 0 & 0 & $46.5 \pm 3.31$ \\
89 & 10 & 1 & $67.3 \pm 1.65$ \\
88 & 10 & 2 & $54.2 \pm 3.28$
\end{tabular}
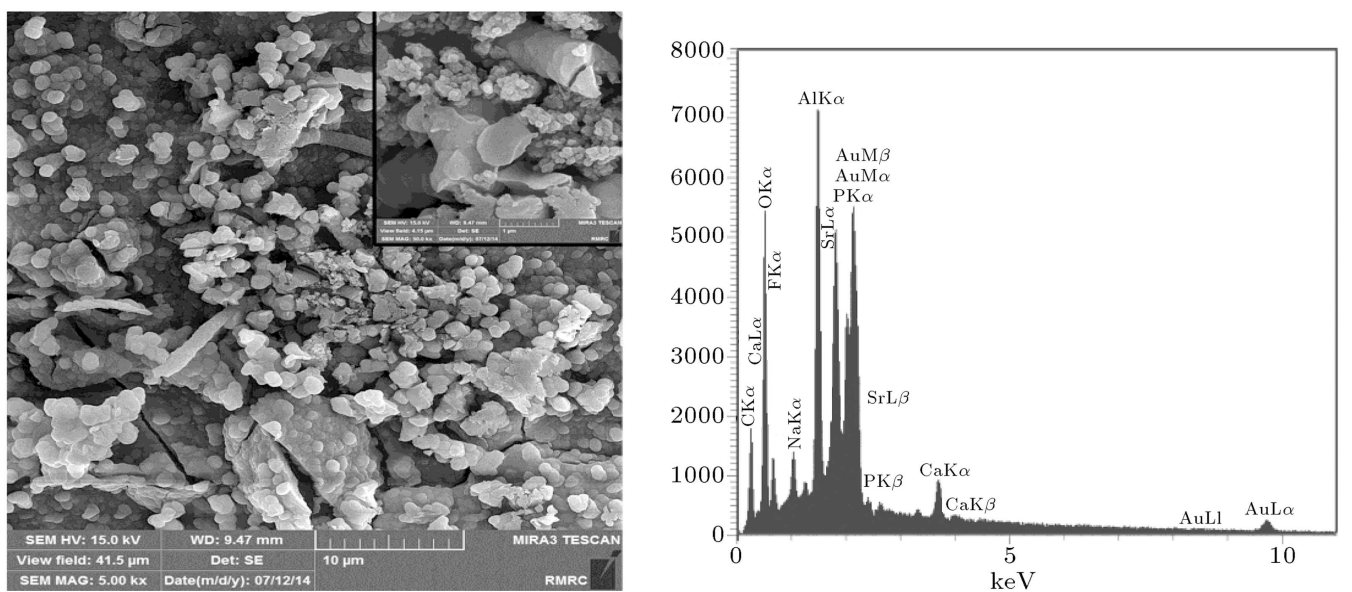

Figure 5. SEM image of particles of ceramic constituents of GIC and EDX analyses.
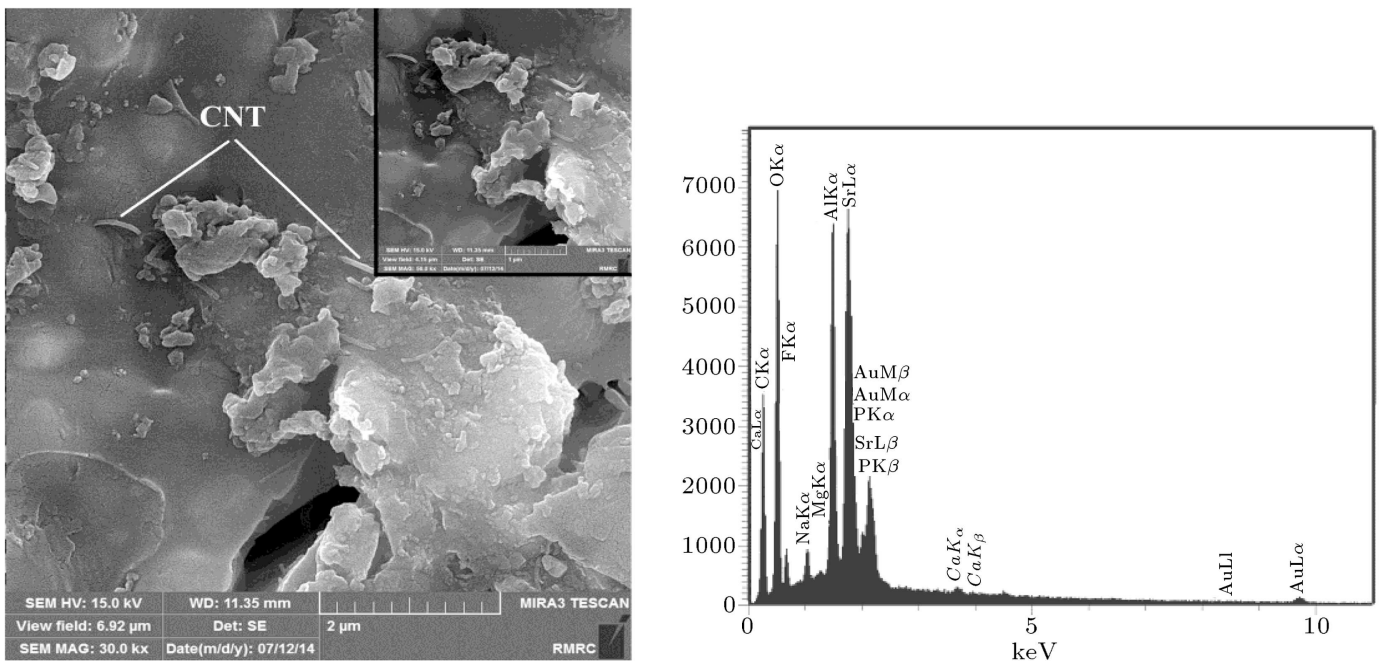

Figure 6. SEM image of nanocomposite composite with carbon nanotubes and bioglass nanopaticles as well as EDX analysis. 
is due to a decrease in bond strength between ceramic and polymeric constituents of GIC.

In fact, because of distribution of CNT particles in the ceramic constituent, they might significantly increase the flexural strength. It was generally concluded from flexural strength test that CNT particles are involved in acid-base reaction of GIC and react with organic and non-organic compositions of GIC network through calcium and phosphate ions. Therefore, by incorporating CNT into the powder composition of GIC, after attack of proton acid (polymeric liquid) to ceramic particles, the calcium ions of bioglass cause formation of saline bridges and cross-linking, which is accompanied by reinforcement of ionomer base. It has been shown that formation of stronger bonds between organic and non-organic networks can lead to a significant increase in mechanical strength of the final cement $(P<0.001)$. To calculate 3 -point flexural strength, the following equation was used:

$$
\sigma_{f}=3 F L / 2 b d^{2}
$$

where $\sigma_{f}$ is the flexural strength for 3-point flexural test, $F$ is the fraction force, $L$ is the distance between the two laps, $b$ is the width of the sample, and $d$ is the thickness of the sample.

\subsubsection{Surface toughness test}

GIC exhibits relatively low resistance to erosion. Therefore, it might be eroded and lose its anatomic form due to erosive or masticatory forces. Its surface might lose its flat and regular configurations due to extrusion of glass particles. During polishing, its cement surface might lose its uniform and flat structure. As a result, this material is not used to restore $\mathrm{Cl} \mathrm{I}$ and $\mathrm{Cl}$ II cavities. In this regard, the results of GIC and nanocomposite samples are shown in Table 3 . The samples were prepared in an acrylic mold and tested by an erosion test machine at a speed of $v=20 \mathrm{Hr}$ and disc rotation of $45 \mathrm{rpm}$ for 5 minutes. The results showed that GIC lost $32 \mathrm{wt} \%$, while nanocomposite exhibited 19 wt \% reduction. Therefore, it can be concluded that the presence of CNT particles can increase resistance to erosion.

\subsection{Biometrical test of the synthesized nanocomposite}

One of the signs of bioactivity is the ability to form apatite in SBF solution on the surface of GIC/Carbon Nanotubes/Bioglass, which might occur in two ways:

Table 3. Resistance of erosion in GIC and nano-composite.

\begin{tabular}{ccc}
\hline & GIC & Nano-composite \\
\hline Initial weight $(\mathrm{gr})$ & 0.169 & 0.324 \\
Secondary weight $(\mathrm{gr})$ & 0.115 & 0.264 \\
\hline
\end{tabular}

1. Figure 7 shows the SEM images of GIC mixed with polymeric solution as wells as deposited apatite before and after bioadaptation test of samples in SBF solution. Figure 7(a) shows the level of composite before submersion in the solution. Figure $7(\mathrm{~b})$ shows the formation of apatite crystals on the surface of composites after 14 days. As shown in the image, the relatively flat surfaces of cement have become porous and irregular after submersion. Apatite particles were deposited widely with a brighter color compared to the surface of the cement. According to the results of EDX, the ions of calcium and phosphorus after 14 days have increased, and the apatite crystals have been formed on its surface completely;

2. The process of synthetic formation of apatite on synthesized composites is influenced by different environmental factors, including its concentration, value, structure, and composition. Kim et al. proposed the mechanism of apatite formation, referred to as "Kim's Theory" [61]. An atomic percentage machine was used to study atomic absorption of calcium and its absorption percentage. In this method, after release of this element from the SBF solution, the level of calcium atomic absorption was defined, which showed less bioactive materials. A higher percentage of calcium in the solution indicated less absorption by the material, resulting in less bioactivity. Figure 8 shows the process of formation of apatite on the surface of bioactive material. To test atomic absorption, the concentration of calcium in SBF solution was measured, which was regarded as the control sample. The concentration of calcium in the control sample was $34 \mathrm{ppm}$ (dashed lines in Figure 9). Then, the concentration of calcium was registered on the 7 th and 14 th days. As shown in Figure 9, on the 7th day, absorption of calcium ion by GIC was higher (25 ppm), while it was $28 \mathrm{ppm}$ on the 14th day. Therefore, it can be concluded that due to the distribution of CNT particles in the composite, absorption of calcium is inhibited. On the other hand, the results on the 14th day showed the integration of bioglass particles into the material, which was accompanied by an increase of $23 \mathrm{ppm}$ in the absorption of calcium ion by composite material, demonstrating higher level of absorption compared with GIC on the 14th day. As a result, it can be concluded that bioglass particles within the composite can increase bioactivity and formation of HA crystals on the surface of material.

\subsection{In vitro biocompatibility}

\subsubsection{MTT assays}

Figure 10 presents the percentages of viable cells exposed to four concentrations of extracts in the three 

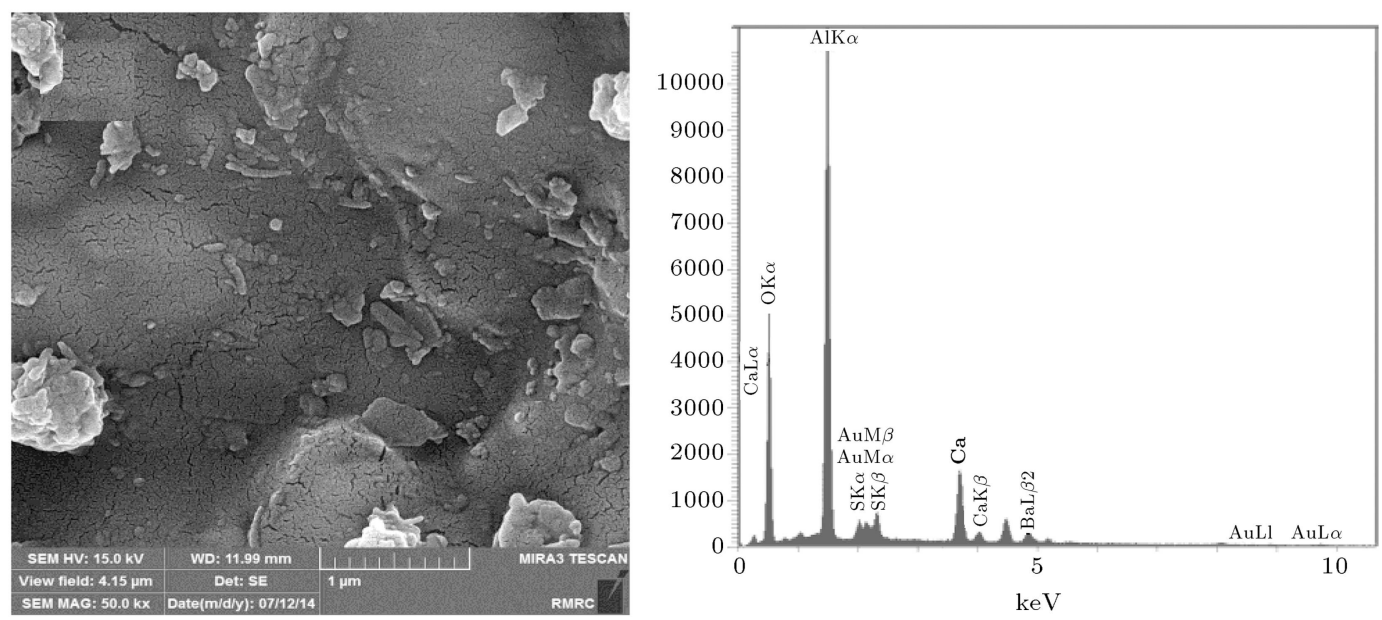

(a)
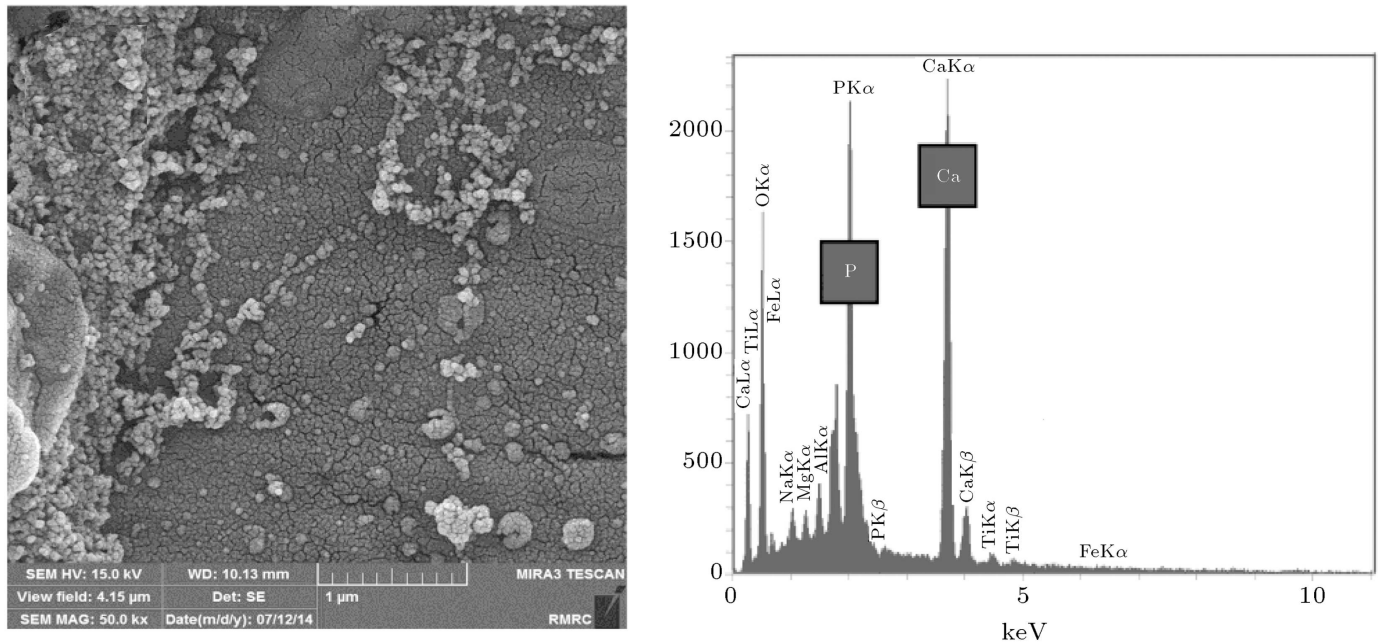

(b)

Figure 7. SEM image of composite: (a) Before submersion; and (b) after submersion in SBF solution.

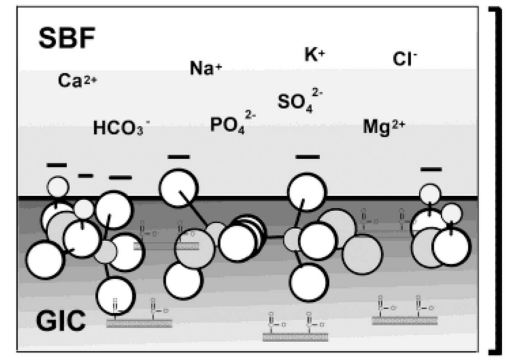

$\mathrm{Ca}: \bigcirc$
$\mathrm{OH}: \bigcirc$

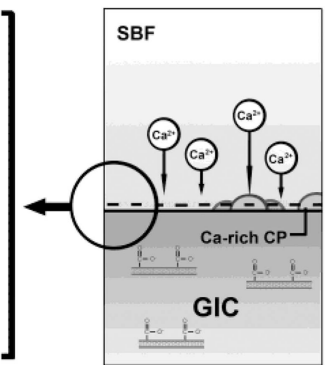

Formation of

Ca-rich $\mathrm{CP}$
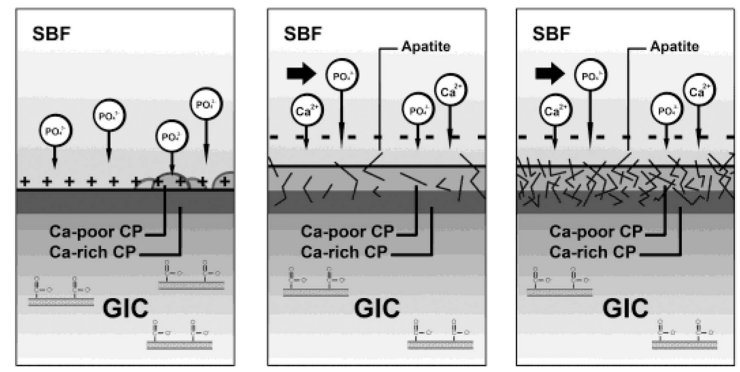

Soaking time in SBF

Figure 8. A scheme of carbon ion absorption in SBF solution on 7th and 14th days.

groups. The percentages of cell viability exposed to undiluted extracts from GIC $(52.65 \%)$ were not different from those of $1 \%$ CNT-GIC (75.46\%), but significantly less than those of $2 \%$ CNT-GIC (100.77\%). The percentages of cell viability of fully concentrated $1 \%$ CNT-GIC group were not different from those of fully concentrated $2 \%$ CNT-GIC and GIC, a half- concentrated GIC, 2\% CNT-GIC and GIC, and a quarter-concentrated GIC.

The percentages of cell viability exposed to $1: 1$, $1: 2$, and 1:4 diluted extracts were not significantly different between the five groups. The cell viability was likely to depend on extract concentration: The lower the concentration, the higher the cell viability. 


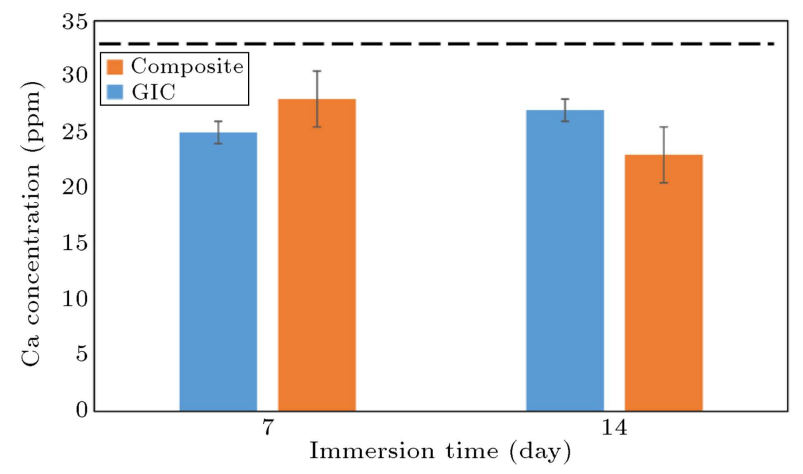

Figure 9. Absorption of calcium ione of SBF solution by composite material on 7 th and 14 th days.

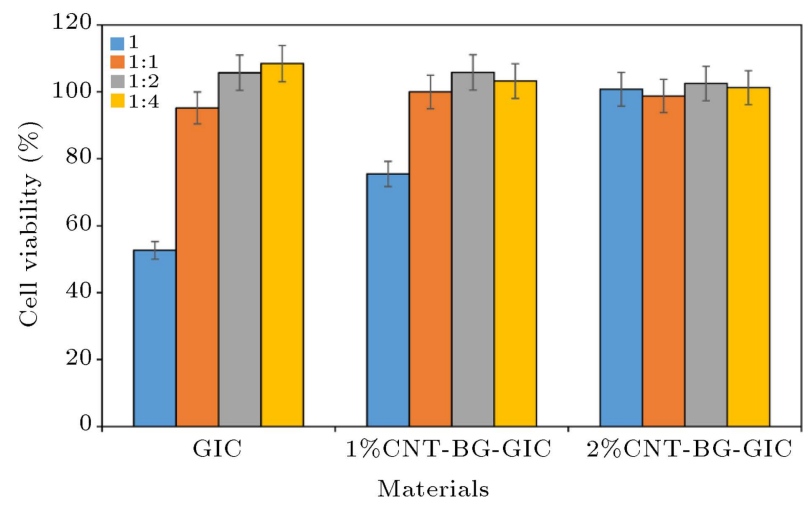

Figure 10. Percentage of cell viability exposed to 4 concentrations of extracts from all groups.
$1: 1$

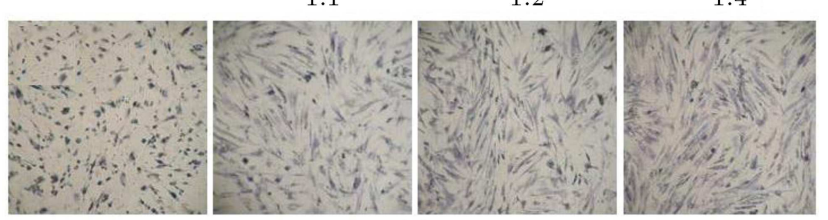

(a)
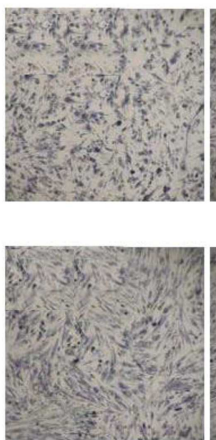

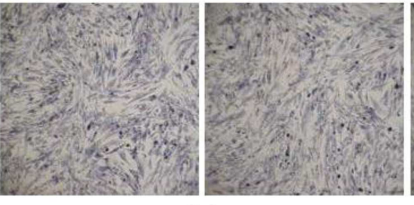

(b)

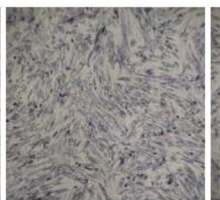

(c)
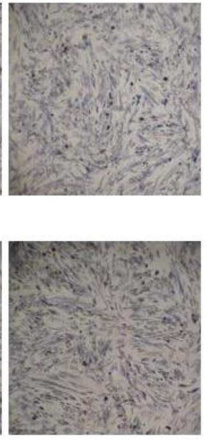

Figure 11. Cell morphology exposed to 4 concentrations of extracts from all three material groups: (a) GIC; (b) $1 \%$ GIC-CNT-BG; and (c) $2 \%$ GIC-CNT-BG.

\subsubsection{Cell morphology}

Figure 11 presents the morphology of PDL fibroblasts exposed to various concentrations of extracts from all the five groups. Most of the cells exposed to undiluted GIC extracts were round-shaped, with fewer cyto-

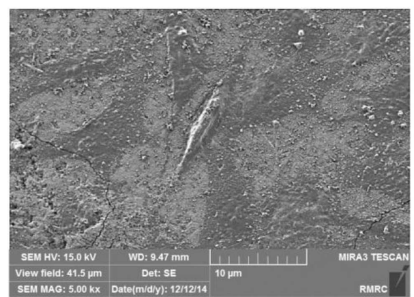

(a)

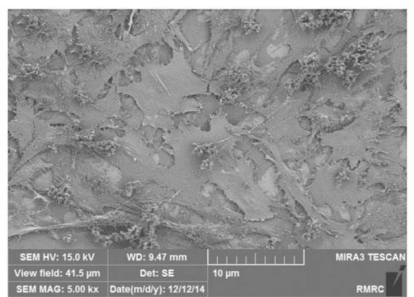

(b)
Figure 12. SEM images of cell morphology of PDL fibroblast-like cells on: (a) GIC-CNT-BG composite (6.35 wt\%); and (b) REF after $48 \mathrm{~h}$ of cultivation.

plasmic extensions and dispersive appearance. Some cells exposed to undiluted 1\% GIC-CNT-BG extracts exhibited round shapes like those from the GIC groups, but they were slightly confluent. However, the cells from these groups were more spindle-shaped and more confluent after they were exposed to the more diluted concentrations. In contrast, most of the cells exposed to GIC were spindle-shaped and confluent at all the concentrations. The cells exposed to $2 \%$ GIC-CNT-BG at all the concentrations tended to be spindle-shaped and confluent like those from the GIC groups.

The measured cell viabilities, Il-6, collagen, and osteocalcin synthesis indicated no negative cellular behavior of the CNT. Generally, BG proved a biocompatible and bioactive biomaterial with high surface reactivity. The cell morphology of PDL fibroblasts was observed under a SEM after 48 hours of incubation on different sample surfaces (Figure 12). PDL fibroblasts were scattered widely and flattened on the BG surface. They were polygonal in shape with filopodia or very thin extensions. The cells did not exhibit any preferred orientation. Some appeared thicker in the central area of the nucleus and flattened in the periphery. Furthermore, in some areas of the sample, the PDL fibroblasts began formation of a multilayer structure, although cell proliferation and viability of PDL fibroblasts on BG strongly decreased compared to the reference material after 48 hours of cultivation. The cell density on GIC-CNT-BG composite was much lower compared to pure BG samples. Furthermore, the morphology of PDL fibroblasts on BG-MWCNT was polygonal and some exhibited delayed spreading. As discussed above, bioactivity of nanomaterials depends on various factors, including purity, morphology, and concentration of CNTs. Consequently, if cell DNA is fragmented or cell organelles like lysosomes are damaged through MWCNT, the cell morphology is also affected. Cell spreading and cytoskeleton expression are inhibited by apoptotic and necrotic effects. Several studies have shown that changes in the cell morphology are the typical effect of CNTs on adherent growing cells $[62,63]$. Despite extensive research on CNT-reinforced biomaterials, there are inconclusive results in relation to the cytotoxicity of CNTs and further research is necessary 
to achieve further knowledge on the mechanism of interaction of CNT (embedded in a matrix material or protruding from a surface) with relevant cells.

\section{Conclusion}

In the present study, GIC was prepared through the fusion method. To increase the mechanical strength and bioadaptation, carbon nanotubes manufactured by electrical arc and bioglass nanoparticles manufactured by fusion method were incorporated into GIC. The results of mechanical analyses showed that CNT can increase the compressive strength and resistance to erosion due to its wide distribution. On the other hand, incorporation of bioglass nanoparticles can increase absorption of calcium in SBF solution, which was accompanied by an increase in bioadaptability of the sample. The electrical conductivity of BG increased by 8 orders of magnitude after incorporation of $6.35 \mathrm{wt} \%$ CNTs, which is due to the formation of a percolating network of CNTs within the dense BG matrix. The in-vitro cell activity on the materials evaluated using a cell line (PDL fibroblasts) suggested that CNT-BG composite inhibited the attachment of cell line cultures. Fewer cells were observed on the composite surface. The cytoskeleton was not expressed, and no dense monolayer was formed for GIC-CNT-BG composite compared to pure BG. Therefore, further studies on composite substrates should be carried out with longer cell culture times to assess the long-term biological compatibility of the material. Based on the results above, this material can function as a lining and sealing filler in dentistry.

\section{Acknowledgments}

This study was supported financially by Vice Chancellor for Research and Technology of Isfahan University of Medical Sciences (Grant number 293346). Also, the authors would like to acknowledge Prof. Abbas Ali Khademi, Prof. Farnaz Nejatidanesh and Prof. Omid Savabi, Torabinejad Dental Materials Research Center, School of Dentistry, Isfahan University of Medical Sciences, Iran, for their kind help and assistance.

\section{References}

1. Hench, L.L. and Polak, J.M. "Third-generation biomedical materials", Science, 295, pp. 1014-1017 (2002).

2. Mount, G. and Hume, W., Preservation and Restoration of Tooth Structure, Mosby (1998).

3. Icholson, J.W. "Chemistry of glass-ionomer cements: A review", Biomaterials, 19, pp. 485-494 (1998).

4. Cehreli, S.B., Tirali, R.E., Yalcinkaya, Z. and Cehrel, Z.C. "Microleakage of newly developed glass carbomer cement in primary teeth", Eur. J. Dent., 7(1), pp. 1521 (2013).

5. De Souza Costa, C.A., Ribeiro, A.P.D., Aparecida Giro, E.M., Randall, R.C. and Hebling, J. "Pulp response after application of two resin modified glass ionomer cements (RMGICs) in deep cavities of prepared human teeth", Dental Materials, 27(7), pp. e158-e70 (2011).

6. Al-Angari, S.S., Hara, A.T., Chu, T.M., Platt, J., Eckert, G. and Cook, N.B. "Physicomechanical properties of a zinc-reinforced glass ionomer restorative material", J. Oral Science, 56(1), pp. 11-16 (2014).

7. Moshaverinia, A., Ansari, S., Moshaverinia, M., Roohpour, N., Darr, J.A. and Rehman, I. "Effects of incorporation of hydroxyapatite and fluroapatite nanobioceramics into conventional glass ionomer cements", Biomaterialia, 4, pp. 432-440 (2008).

8. Kroto, H.W., Heath, J.R., O'brien, S.C., Curl, R.F. and Smalley, R.E. "C60: buckminsterfullerene", $\mathrm{Na}$ ture, 318, pp. 162-163 (1985).

9. Iijima, S. "Helical microtubules of graphitic carbon", Nature, 354, pp. 56-58 (1991).

10. Ganguly, S., Bhuyan, M., Allie, L. and Aglan, H. "Effect of multi-walled carbon nanotube reinforcement on the fracture behavior of a tetrafunctional epoxy", J. Materials Science, 40(13), pp. 3593-3595 (2005).

11. Khare, R. and Bose, S. "Carbon nanotube based composites - A review", J. Minerals \& Materials Characterization \& Engineering, 4(1), pp. 31-46 (2005).

12. Boccaccini, A.R., Cho, J., Subhani, T., Kaya, C. and Kayac, F. "Deposition of carbon nanotube-ceramic nanocomposites", J. European Ceramic Society, 30, pp. 1115-1129 (2010).

13. Chen, Y., Zhang, Y.Q., Zhang, T.H., Gan, C.H., Zheng, C.Y. and Yu, G. "Carbon nanotube reinforced hydroxyapatite composite coatings produced through laser surface alloying", Carbon, 44, pp. 37-45 (2006).

14. Hahn, B.D., Lee, J.M., Park, D.S., Choi, J.J. and Yoon, J.R. "Mechanical and in vitro biological performances of hydroxyapatite-carbon nanotube composite coatings deposited on Ti by aerosol deposition", Acta Biomaterialia, 5, pp. 3205-3214 (2009).

15. Kaya, C. "Electrophoretic deposition of carbon nanotube-reinforced hydroxyapatite bioactive layers on $\mathrm{Ti}-$ 6Al-4V alloys for biomedical applications", Ceramics International, 34, pp. 1843-1847 (2008).

16. Balani, K., Anderson, R., Laha, T., Andara, M. and Tercero, J. "Plasma-sprayed carbon nanotube reinforced hydroxyapatite coatings and their interaction with human osteoblasts in vitro", Biomaterials, 28(4), pp. 618-624 (2007).

17. Akasaka, T., Watari, F., Sato, Y. and Tohji, K. "Apatite formation on carbon nanotubes", Materials Science and Engineering C, 26, pp. 675-678 (2006).

18. Zhao, B., Hu, H., Mandal, S.K. and Haddon, R.C. "A bone mimic based on the self-assembly of hydroxyapatite on chemically functionalized single-walled carbon nanotubes", Chem. Mater., 17, pp. 3235-3241 (2005). 
19. Stout, D.A. and Webster, T.J. "Carbon nanotubes for stem cell control", Materials Today, 15, pp. 312-319 (2012).

20. Cicchetti, R., Divizia, M., Valentini, F. and Argentin, G. "Effects of single-wall carbon nanotubes in human cells of the oral cavity: Geno-cytotoxic risk", Toxicology in Vitro, 25, pp. 1811-1819 (2011).

21. Hirata, E., Akasaka, T., Uo, M., Takita, H., Watari, F. and Yokoyama, A. "Carbon nanotube-coating accelerated cell adhesion and proliferation on poly (Llactide)", Appl. Surf. Sci., 262, pp. 24-27 (2012).

22. Lu, F., Gu, L., Meziani, M.J., Wang, X., Luo, P.G., Veca, L.M., Cao, L. and Sun, Y.P. "Advances in bioapplications of carbon nanotubes", Adv. Mater., 21, pp. 139-152 (2009).

23. Kolosnjaj, J., Szwarc, H. and Moussa, F. "Toxicity studies on carbon nanotubes: State of the art", ECS Trans., 35(25), pp. 121-134 (2011).

24. White, A.A. and Best, S.M. "Hydroxyapatite-carbon nanotube composites for biomedical applications: A review", Int. J. Appl. Ceram. Technol., 4(1), pp. 1-13 (2007).

25. Mei, F., Zhong, J., Yang, X., Ouyang, X., Zhang, S., Hu, X., Ma, Q., Lu, J., Ryu, S. and Deng, X. "Improved biological characteristics of poly(L-Lactic Acid) electrospun membrane by incorporation of multiwalled carbon nanotubes/hydroxyapatite nanoparticles", Biomacromolecules, 8, pp. 3729-3735 (2007).

26. Zhang, F., Xia, Y., Xu, L. and Gu, N. "Surface modification and microstructure of single-walled carbon nanotubes for dental resin-based composites", $J$. Biomed Mater Res Part B: Appl Biomater, 86B, pp. 90-97 (2008).

27. Madani, S.Y., Mandel, A. and Seifalian, A.M. "A concise review of carbon nanotube's toxicology", Nano Rev., 4 (2013).

28. Li, X.M., Fan, Y.B. and Watari, F. "Current investigations into carbon nanotubes for biomedical application", Biomed Mater., 5(2) (2010). DOI: 10.1088/1748$6041 / 5 / 2 / 022001$

29. Pichardo, S., Gutierrez-Praena, D., Puerto, M., Sanchez, E., Grilo, A. and Carnean, A.M. "Oxidative stress responses to carboxylic acid functionalized single wall carbon nanotubes on the human intestinal cell line Caco-2", Toxicol in Vitro, 26(5), pp. 672-677 (2012).

30. Andon, F.T. and Fadeel, B. "Programmed cell death: molecular mechanisms and implications for safety assessment of nanomaterials", Acc. Chem. Res., 46(3), pp. 733-742 (2013).

31. Mortazavi, V., Nahrkhalaji, M.M., Fathi, M.H., Mousavi, S.B. and Esfahani, B.N. "Antibacterial effects of sol-gel-derived bioactive glass nanoparticle on aerobic bacteria", J Biomedical Materials Research. Part A, 94, pp. 160-168 (2010).

32. Lindfors, N.C., Hyvonen, P., Nyyssonen, M., Kirjavainen, M. and Kankare, J. "Bioactive glass as bone graft substitute in treatment of osteomyelitis", J. Bone, 47, pp. 212-218 (2010).
33. Yli-Urpo, H., Lassila, V.J., Narhi, T. and Vallittu, P.K. "Compressive strength and surface characterization of glass ionomer cements modified by particles of bioactive glass", Dental Materials, 21, pp. 201-209 (2005).

34. Chen, Q.Z., Efthymiou, A., Salih, V. and Boccaccini, A.R. "Bioglass- derived glass-ceramic scaffolds: study of cell proliferation and scaffold degradation in vitro", J. Biomed. Mater. Res. A, 84A(4), pp. 1049-1060 (2008).

35. Xynos, I.D., Edgar, A.J., Buttery, L.D.K., Hench, L.L. and Polak, J.M. "Ionic products of bioactive glass dissolution increase proliferation of human osteoblasts and induce insulin-like growth factor II mRNA expression and protein synthesis", Biochem. Bioph. Res. Co., 276(2), pp. 461-465 (2000).

36. Day, R.M., Boccaccini, A.R., Shurey, S., Roether, J.A., Forbes, A. and Hench, L.L. "Assessment of polyglycolic acid mesh and bioactive glass for softtissue engineering scaffolds", Biomaterials, 25(27), pp. $5857-5866$ (2004).

37. Zhang, D., Lepparanta, O., Munukka, E., Ylanen, H., Viljanen, M.K. and Eerola, E. "Antibacterial effects and dissolution behavior of six bioactive glasses", $J$. Biomed. Mater. Res. A, 93A(2), pp. 475-483 (2010).

38. Gorustovich, A.A., Roether, J.A. and Boccaccini, A.R. "Effect of bioactive glasses on angiogenesis: a review of in vitro and in vivo evidences", Tissue Eng. Part B-Rev., 16(2), pp. 199-207 (2010).

39. Hench, L.L., Splinter, R.J., Allen, W.C. and Greenlee, T.K. "Bonding mechanisms at the interface of ceramic prosthetic materials", J. Biomed. Mater. Res. A., 5(6), p. 117 (1971)

40. Hench, L.L. "The story of bioglass", J. Mater. Sci.Mater M., 17(11), pp. 967-978 (2006).

41. Anderson, A.B., Dallmier, A.W., Chudzik, S.J., Duran, L.W., Guire, P.E. and Hergenrother, R.W. "Technologies for the surface modification of biomaterials. In: Yaszemski, MJ, Trantolo, DJ, Lewandrowski, K-U", Hasirci, V, Altobelli, D.E, Wise, D.L, Eds.; Biomaterials in Orthopedics., 2nd Ed., CRC Press; pp. 93-148 (2003).

42. Wang, J.X., Fan, Y.B., Gao, Y., Hu, Q.H. and Wang, T.C. " $\mathrm{TiO}_{2}$ nanoparticles translocation and potential toxicological effect in rats after intraarticular injection", Biomaterials, 30(27), pp. 4590-4600 (2009)

43. Geim, A.K. and Novoselov, K.S. "The rise of grapheme", Nat. Mater., 6(3), pp. 183-191 (2007).

44. Lee, C., Wei, X.D., Kysar, J.W. and Hone, J. "Measurement of the elastic properties and intrinsic strength of monolayer grapheme", Science, 321(5887), pp. 385-388 (2008).

45. Balandin, A.A., Ghosh, S., Bao, W.Z., Calizo, I., Teweldebrhan, D. and Miao, F. "Superior thermal conductivity of single-layer graphene", Nano Lett., 8(3), pp. 902-907 (2008). 
46. Pumera, M. "Electrochemistry of graphene: new horizons for sensing and energy storage', Chem. Rec., 9(4), pp. 211-223 (2009).

47. Porwal, H., Grasso, S. and Reece, M. "Review of graphene-ceramic matrix composites", Adv. Appl. Ceram., $112(8)$, p. 443 (2013).

48. Mohanty, N. and Berry, V. "Graphene-based singlebacterium resolution biodevice and DNA transistor: interfacing graphene derivatives with nanoscale and microscale biocomponents", Nano Lett., 8(12), pp. 4469-4476 (2008).

49. Khan, U., May, P., Porwal, H., Nawaz, K. and Coleman, J.N. "Improved adhesive strength and toughness of polyvinyl acetate glue on addition of small quantities of graphene", Acs. Appl. Mater. Interface., 5(4), pp. 1423-1428 (2013).

50. Wu, J.B., Agrawal, M., Becerril, H.A., Bao, Z.N., Liu, Z.F. and Chen, Y.S. "Organic light-emitting diodes on solution-processed graphene transparent electrodes", ACS Nano, 4(1), pp. 43-48 (2010).

51. Iijima, S. "Helical microtubules of graphitic carbon", Nature, 354(6348), pp. 56-58 (1991).

52. Inam, F., Yan, H.X., Jayaseelan, D.D., Peijs, T. and Reece, M.J. "Electrically conductive alumina-carbon nanocomposites prepared by spark plasma sintering", J. Eur. Ceram. Soc., 30(2), pp. 153-157 (2010).

53. Porwal, H., Tatarko, P., Grasso, S., Khaliq, J., Dlouhy, I. and Reece, M. "Graphene reinforced alumina nanocomposites", Carbon, 64, pp. 359-369 (2013).

54. Porwal, H,. Tatarko, P., Saggar, R., Grasso, S., Kumar Mani, M. and Dlouhy, I. "Tribological properties of silica-graphene nanoplatelet composites", Ceram Int., 40(8), pp. 12067-12074 (2014).

55. Porwal, H., Grasso, S., Mani, M.K. and Reece, M.J. "In situ reduction of graphene oxide nanoplatelet during spark plasma sintering of a silica matrix composite", J. Eur. Ceram. Soc., 34(14), pp. 3357-3364 (2014).

56. White, A.A., Kinloch, I.A., Windle, A.H. and Best, S.M. "Optimization of the sintering atmosphere for high-density hydroxyapatite-carbon nanotube composites", J. R. Soc. Interface, 7, pp. S529-S539 (2010).

57. White, A.A., Windle, A.H. and Kinloch, I.A. "Best SM. Preparation and properties of carbon nanotubereinforced hydroxyapatite", Bioceramics, 20, pp. 419422 (2008).

58. Phillips, R. and Alph, W. "The glass ionomer cement", J. American Dental Ass., 120, pp. 19-20 (1990).

59. Mount, G.J. "Glass ionomers: a review of their current status", Operative Dental, 24(2), pp. 115-124 (1999).

60. Monshi, A., Foroughi, M.R. and Monshi, M.R. "Modified scherrer equation to estimate more accurately nano-crystallite size using XRD", World J. Nano. Sci. and Eng., 2, pp. 154-160 (2012).
61. Kim, H.M., Himeno, T., Kokubo, T. and Nakamura, T. "Process and kinetics of bonelike apatite formation on sintered hydroxyapatite in a simulated body fluid", Biomaterials, 26, pp. 4366-4373 (2005).

62. Patlolla, A., Knighten, B. and Tchounwou, P. "Multiwalled carbon nanotubes induce cytotoxicity, genotoxicity and apoptosis in normal human dermal fibroblast cells", Ethn. Dis., 20(1), pp. S1-65-72 (2010).

63. Monteiro-Riviere, N.A., Nemanich, R.J., Inman, A.O., Wang, Y.Y. and Riviere, J.E. "Multi-walled carbon nanotube interactions with human epidermal keratinocytes", Toxicol Lett., 155(3), pp. 377-384 (2005).

\section{Biographies}

Mohammad Reza Foroughi is Dental Materials PhD candidate at Dental Materials Research Center, Isfahan University of Medical Sciences (IUMS), Isfahan, Iran. He has three Gold medals and 10 patents to Nanomaterials and Biomaterials. He has participated in writing more than 40 papers published in national and international journals and conference proceedings in the fields of nano-biomaterials and tissue engineering. He wrote three books, including "Principle of Nanotechnology, Physical Metallurgy and Advanced Materials, Introduction of Rapid prototyping".

Maryam Khoroushi received her DDS and MSc degrees in 1991 and 1997, respectively, from Isfahan University of Medical Sciences (IUMS), Isfahan, Iran. She currently works as a Professor in Dental Materials Research Center and Department of Operative Dentistry, IUMS, Iran. She has served as editor-inchief in Journal of Dental School, IUMS from 20072014. At present, besides her academic activities, she is also Editor-in-Chief of Dental Research Journal, IUMS, Isfahan, Iran. She has participated in writing more than 70 papers published in national and international journals and conference proceedings in the fields of restorative dentistry, dental materials, and biomaterials. Her current research interests are applying of nanobiomaterials and stem cells in dentistry.

Reihaneh Nazem is a DDS, MSc, Cosmetic, and operative dentist, professional dental photographer, Associate Professor, Dental Materials Research Center and Department of Operative Dentistry, School of Dentistry, Qazvin University of Medical Sciences, Qazvin, Iran.

Elham Akbarian Tefaghi is a dentist and graduated from Islamic Azad University, Khorasgan Branch, Isfahan, Iran. 